\title{
Glutamate-Positive Corticocortical Neurons in the Somatic Sensory Areas I and II of Cats
}

\author{
Fiorenzo Conti, Mara Fabri, and Tullio Manzoni \\ Institute of Human Physiology, University of Ancona, I-60131 Ancona, Italy
}

Combined retrograde transport-immunocytochemical experiments were carried out on cats to study the morphology, laminar distribution, and percentages of corticocortical projecting neurons of somatosensory area I (SI) and II (SII) showing immunoreactivity to an antiserum raised against the amino acid glutamate (Glu).

A previously characterized anti-Glu serum (Conti et al., 1987a, b; Hepler et al., 1987) was used in conjunction with HRP. This tracer was injected either in SI to label retrogradely neurons in ipsilateral SII (SII-SI association neurons) and contralateral SI (SI-SI callosal neurons) or in SII to label retrogradely neurons in ipsilateral SI (SI-SII association neurons) and contralateral SII (SII-SII callosal neurons). In sections from SI and SII processed for simultaneous visualization of Glu and HRP (Bowker et al., 1982), and containing the cells from which every one of the 4 corticocortical projections arise, 3 types of labeled neurons were observed: (1) single-labeled neurons showing the homogeneous brown immunoreaction product of Glu (Glu-positive neurons); (2) single-labeled neurons containing the granular black reaction product of retrogradely transported HRP (Glu-negative, association or callosal neurons); and (3) double-labeled neurons in which both the black HRP granules and the brown immunostaining were present (Glu-positive, association or callosal neurons). Double-labeled neurons were all pyramidal in shape and were distributed intermingled with Glunegative corticocortical neurons in all layers of SI and SII known to give rise to association and callosal projections. Counts from 25- $\mu \mathrm{m}$-thick sections showed that of 432 association and callosal neurons sampled from SI and SII, 214 $(49.5 \%)$ were Glu-negative and $218(50.5 \%)$ Glu-positive. In counts carried out on $5-\mu \mathrm{m}$-thick sections, the percentage of Glu-positive corticocortical neurons raised to about $70 \%$. The 2 populations of single- and double-labeled corticocortical neurons showed no difference in their perikaryal cross-sectional areas.

The present results show that a large fraction of association and callosal neurons of SI and SII are immunoreactive for Glu, and, therefore, these neurons probably use this excitatory amino acid, or a closely related compound, as neurotransmitter.

Received July 22, 198\%; revised Nov. 2, 1987; accepted Nov. 6, 1987

This work was supported by Ministero della Pubblica Istruzione and by Regione Marche. We gratefully acknowledge Drs. A. Rustioni and P. Petrusz for providing us the anti-Glu serum, Miss S. Modena for reviewing the English, and Mr. A Cocilova and Miss C. Feri for technical assistance.

Correspondence should be addressed to Dr. T. Manzoni, Institute of Human Physiology, University of Ancona, Via Ranieri-Monte-d'Ago, I-60131 Ancona, Italy.

Copyright (C) 1988 Society for Neuroscience $0270-6474 / 88 / 082948-13 \$ 02.00 / 0$
The amino acids glutamate (Glu) and aspartate (Asp) have been associated with cortical function since the early pharmacological studies of Krnjević and Phillis (1963). Glu and Asp were later proposed as excitatory synaptic transmitters (see Johnson, 1972, and Krnjević and Phillis, 1974, for reviews), and since then various techniques have been employed to identify cortical Glu/ $\Lambda$ sp-ergic neurons and pathways. Lesion-induced reduction of endogenous level and stimulated release and uptake of these amino acids were demonstrated in many structures receiving cortical projections (Fonnum and Malthe-Sorenssen, 1981; Fagg and Foster, 1983; Fonnum, 1984; Streit, 1984). Following iontophoretic delivery of their specific antagonists, block of corticofugal excitatory effects was also reported in some of these structures (Mayer and Westbrook, 1987). Tritiated $D$-aspartate (D- ${ }^{3} \mathrm{H}-\mathrm{Asp}$ ) was also used as selective retrograde marker of cortical projecting neurons supposed to use Glu and/or Asp as neurotransmitter (Streit, 1980). Labeling was obtained of cortical neurons projecting to the spinal cord and the cuneate nucleus (Rustioni and Cuénod, 1982), ventrobasal complex (Rustioni et al., 1983; Jones, 1985), lateral geniculate (Baughman and Gilbert, 1981), neostriatum and substantia nigra (Streit, 1980), and superior colliculus (Matute and Streit, 1985). These studies indicate that Glu and/or Asp might be the excitatory neurotransmitter used by nearly all corticofugal systems. Evidence that corticocortical projecting neurons may also use these excitatory amino acids was provided by recent experiments on cats, showing that association and callosal neurons could be retrogradely labeled with $\mathrm{D}-{ }^{3} \mathrm{H}-\mathrm{Asp}$ in the somatic sensory areas I (SI) and II (SII) (Manzoni et al., 1986; Barbaresi et al., 1987). Because of the limitations inherent to this technique, several important questions remained unanswered. One question was whether Glu or Asp is the neurotransmitter of corticocortical neurons labeled with $\mathrm{D}^{-3} \mathrm{H}$-Asp. This question could not be answered since this marker does not allow for differentiating neurons using Glu from those using Asp, being that L-Glu, L-Asp, and their $\mathrm{D}$-forms accumulated in neurons by the same highaffinity uptake mechanism (Balcar and Johnston, 1972). Another problem was whether corticocortical projections could arise from more than one neuronal population, each using a different neurotransmitter. The only evidence was that in lower layer III corticocortical neurons labeled with $\mathrm{D}^{3} \mathrm{H}$-Asp were rare compared with those labeled with the unselective tracer HRP. It was argued that these neurons could make up a different, layerspecific class of corticocortical neurons (Barbaresi et al., 1987), yet whether they are a special population of amino acid-ergic neurons that do not accumulate D-asp, i.e., a case of false negativity (Cuénod et al., 1982; Wiklund et al., 1984), or whether they use a different neurotransmitter is still unsettled.

A major progress in the study of neurotransmitters in the cerebral cortex was the demonstration that Glu can be visualized 
Table 1. Summary of experimental cases

\begin{tabular}{|c|c|c|c|c|c|c|c|c|c|}
\hline \multirow[b]{2}{*}{ Animal } & \multirow{2}{*}{$\begin{array}{l}\text { Area } \\
\text { injected } \\
\text { with } \\
\text { HRP } \\
\end{array}$} & \multirow[b]{2}{*}{ Injection site(s) } & \multirow[b]{2}{*}{$\begin{array}{l}\text { Number } \\
\text { of } \\
\text { injections }\end{array}$} & \multirow{2}{*}{$\begin{array}{l}\text { Amount of } \\
\text { HRP per } \\
\text { injection } \\
(\mu l)\end{array}$} & \multirow[b]{2}{*}{$\begin{array}{l}\text { Survival } \\
\text { time (hr) }\end{array}$} & \multicolumn{2}{|l|}{ Fixative } & \multirow[b]{2}{*}{$\begin{array}{l}\text { Postfixa- } \\
\text { tion (hr) }\end{array}$} & \multirow{2}{*}{$\begin{array}{l}\text { Sections } \\
\text { thick- } \\
\text { ness } \\
(\mu \mathrm{m})\end{array}$} \\
\hline & & & & & & $\begin{array}{l}4 \% \text { Car- } \\
\text { bodiimide }\end{array}$ & $\begin{array}{l}4 \% \\
\text { Parafor- } \\
\text { maldehyde }\end{array}$ & & \\
\hline CCG1 & - & - & - & - & - & + & - & 72 & 25 \\
\hline $\mathrm{CCG} 2$ & - & - & - & - & - & + & - & 75 & 25 \\
\hline CCG3 & SII & Forepaw & 3 & 0.25 & 36 & + & + & 72 & 25 \\
\hline CCG4 & SI & Forepaw and trunk & $\begin{array}{l}3 \\
3\end{array}$ & 0.25 & 36 & + & + & 80 & 25 \\
\hline CCG5 & SI & Forepaw and trunk & $\begin{array}{l}3 \\
3\end{array}$ & 0.25 & 32 & + & + & 96 & 25 \\
\hline CCG6 & SI & Trunk & 3 & 0.25 & 38 & + & + & 72 & 25 \\
\hline CCG7 & SI & Forepaw and trunk & $\begin{array}{l}2 \\
6\end{array}$ & 0.25 & 37 & + & + & 96 & 25 \\
\hline CCG8 & SII & Forepaw & 4 & 0.25 & 40 & + & + & 87 & 5,25 \\
\hline
\end{tabular}

in neurons with immunocytochemistry (Storm-Mathisen et al., 1983; Ottersen and Storm-Mathisen, 1984). Hepler et al. (1988) recently produced and characterized an antiserum against Glu that effectively and selectively labels only neurons rich in Glu. Based on other evidence, it was proposed that labeling obtained with this serum in selected experimental conditions probably reflects the neurotransmitter pool of Glu (Conti et al., 1987a). Using this probe, Conti et al. (1987a) studied the laminar distribution and morphology of Glu-positive ncurons in the somatic sensory cortex of rats and monkeys and found that the anti-Glu serum positively marked about $30-50 \%$ of pyramidal neurons both in supragranular and infragranular layers from which corticocortical fibers arise (Jones, 1984).

In the present experiments the question of which neurotransmitter is used by corticocortical neurons was reinvestigated using this anti-Glu serum and HRP in combined immunocytochemical-retrograde transport experiments according to the method introduced by Bowker et al. (1982). This approach provides some advantages with respect to the $\mathrm{D}-{ }^{3} \mathrm{H}$-Asp technique and might give an answer to the above mentioned questions. Whereas HRP retrogradely labels neurons regardless of the neurotransmitter they use, the anti-Glu serum (1) selectively labels Glu-ergic neurons since it is able to differentiate between Glu and other amino acids, including Asp, and (2) appears to give a ncarly complete picture of putative Glu-ergic neurons.

Preliminary results from these experiments have been reported in abstract form (Conti et al., 1987c; Manzoni et al., 1987).

\section{Materials and Methods}

The present research is based on the results from 8 adult cats weighing $2.5-3 \mathrm{~kg}$ (see Table 1). Two cats (CCG1 and CCG2) were used to study the laminar distribution of Glu-positive neurons and the ratio between labeled and unlabeled neurons in SI and SII. On 6 cats (CCG3-CCG8), combined immunocytochemical-retrograde transport experiments were performed.

Surgery and HRP injections. Cats CCG3-CCG8 were premedicated with desamethazone $(1.3 \mathrm{mg} / \mathrm{kg}$, i.m.), anesthetized with ketamine (Ketalar, $33 \mathrm{mg} / \mathrm{kg}$, i.m.), and mounted on a stereotaxic frame. The skull was opened and the dura removed to expose either SI or SII. HRP (Boehringer, grade I; 33\% in sterile saline) was injected by pressure with a glass micropipettc glued to a $5 \mu 1$ Hamilton microsyringc over a period of 10-15 min. The pipette was removed after 10 more min. Since fine topography was unnecessary to the purpose of the present study, injec- tion sites were located by comparing sulcal patterns of experimental animals with the known topography of body representation in SI and SII. In animals with SI injections, HRP was delivered in the cortex of the posterior sygmoid gyrus flanking the medial branch of the ansate sulcus (injections aimed at the trunk representation: Manzoni et al., 1980; McKenna et al., 1981; Felleman et al., 1983), and in the posterior third of the lateral sygmoid gyrus (injections aimed at the hand represcntation: McKenna ct al., 1981; Felleman ct al., 1983). In animals with SII injections, HRP was delivered in the cortex of the anterior ectosylvian gyrus just laterally to the rostral part of the suprasylvian sulcus (Burton et al., 1982). Details on location and number of HRP injections, amount of tracer delivered, and survival time are given in Table 1.

Perfusion and tissue preparation. At the time of sacrifice, animals CCG3-CCG8 were deeply anesthetized (Nembutal, $30 \mathrm{mg} / \mathrm{kg}$, i.p.) and perfused through the ascending aorta with saline followed by $4 \%$ carbodiimide in $0.1 \mathrm{~m}$ phosphate buffer ( $\mathrm{pH} \mathrm{7.4)}$ and $4 \%$ paraformaldehyde in the same buffer. Cats CCG1 and CCG 2 were similarly anesthetized and perfused with saline, followed by $4 \%$ carbodiimide in $0.1 \mathrm{M}$ phosphate buffer ( $\mathrm{pH} 7.4)$. All brains were removed and postfixed for 3-4 $\mathrm{d}$ in $4 \%$ paraformaldehyde. Small blocks were removed from SI and SII, rinsed in PBS, and cut with a Vibratome in $25-\mu \mathrm{m}$-thick sections, cxccpt some blocks from cat CCG8, which werc immersed in sucrose solution $(20-30 \%)$ and cut with a cryostat in 5- $\mu$ m-thick sections. Sections from all blocks were collected in serial groups of 4 . The first sections were processed for HRP histochemistry, the second for combined HRPGlu reaction, and the third counterstained with $0.1 \%$ thionine, while the fourth was kept unprocessed in PBS for some days. In the series from animals CCG1 and CCG2, the first sections were processed for immunocytochemistry, the second counterstained with $0.1 \%$ thionine, and the remaining two kept in PBS.

HRP histochemistry. HRP histochemistry was performed according to the protocol of Bowker et al. (1982). Briefly, sections were rinsed 3

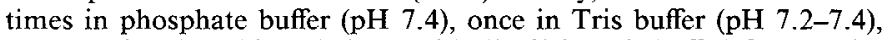
and then incubated in cobalt chloride $(0.5 \%$ in Tris buffer) for $10 \mathrm{~min}$. After 2 rinses in Tris and 2 more in phosphate buffer, sections were incubated in diaminobenzidinc (DAB; $0.02 \%$ in Tris buffer) with $0.01 \%$ $\mathrm{H}_{2} \mathrm{O}_{2}$ for $10-15 \mathrm{~min}$ and finally rinsed 3 times ( 5 min each) in PBS. One of the 2 series processed for HRP was mounted in subbed slides, air-dried, coverslipped, and used as control to check loss of HRP reaction product during immunocytochemical procedure.

Immunocytochemical procedure. Sections used for the combined HRPGlu processing were rinsed in PBS for $15 \mathrm{~min}$ and incubated for $30 \mathrm{~min}$ in normal sheep serum (NSS; $2 \%$ in PBS) to mask nonspecific binding sites (Sternberger, 1986). After a quick rinse in PBS, sections were transferred into the primary antiserum (see below) diluted at 1:8000$1: 12,000$ and incubated overnight at $4^{\circ} \mathrm{C}$. On the following day, sections were rinsed 3 times in PBS, incubated in NSS for $10 \mathrm{~min}$, and immersed in the secondary antiserum (biotinilated goat antirabbit, bGAR; 1:200 in PBS) for about $100 \mathrm{~min}$. Following incubation in bGAR, sections werc rinscd again in PBS (2 rinses; 15 min cach) and transferred into a solution containing the ABC reagents (Hsu et al., 1981). After about $100 \mathrm{~min}$, sections were removed, rinsed in PBS, and incubated in DAB 
(Sigma; $0.075 \%$ in $0.05 \mathrm{M}$ Tris buffer, $\mathrm{pH} 7.6$ ) for $5-7 \mathrm{~min}$. Wet sections were observed under a microscope to assess staining intensity, and incubation was discontinued when staining was considered sufficient to ensure identification of immunoreactive neurons and, at the same time, not so intense as to mask HRP reaction product. Sections were then rinsed for $30 \mathrm{~min}$ in PBS, mounted on slides, air-dried, dehydrated, and coverslipped with DPX. Sections from animals CCG1 and CCG2 were processed in a similar way, except that they were kept in DAB for $10 \mathrm{~min}$. Thin sections from animal CCG8 were processed following a modified protocol (see Conti et al., 1987a).

The anti-Glu serum (n. 482a; Hepler et al., 1988) used in this study was raised in a rabbit against Glu conjugated to keyhole limpet hemocyanin with glutaraldehyde. Details on anti-Glu serum characterization are dealt with in a previous paper (Hepler et al., 1988). In brief, under optimal staining conditions, no cross-reactivity with a scrics of structurally related and biologically significant compounds was observed in immunoabsorption tests; analogous evidence was obtained in immunoblot specificity tests (Hepler et al., 1988). Details on method and antiserum specificity at cortical level are reported by Conti et al. (1987a). In the present histological material only method specificity was tested, by omitting the primary antiserum and processing the sections in the same way as those incubated in the anti-Glu serum. These control sections showed no labeling. Sections were then studied before and after counterstaining with thionine $(0.1 \%)$.

Data analysis. For quantitative data on the laminar distribution of Glu-positive neurons in SI and SII, sections from cats CCG 1 and CCG3 were studied under a $25 \times$ objective of a light microscope and $500-\mu \mathrm{m}$ wide sectors of SI and SII were reproduced with a drawing tube using the criteria described by Conti et al. (1987a). In samples from animals CCG3-CCG8, on which double-labeling experiments were carried out, data were obtained from cortical regions containing HRP retrogradely labeled neurons and showing staining intensity similar to that observed in noninjected animals. Outlines of Glu-positive, HRP-positive and Glu/HRP-positive perikarya were drawn with a camera lucida using a $40 \times$ objective. Only neurons with nuclei occupying a large proportion of the perikarya were drawn, since this indicates a plane of section that is near the center of the cell. Cross-sectional areas of these neurons were measured with a graphic tablet interfaced with an IBM/PC-AT computer.

SII cytoarchitecture and layering were identified according to the description given by Burton et al. (1982); SI cytoarchitecture and layering were identified according to Hassler and Muhs-Clement (1964). In both SI and SII layer III was divided into an outer small-celled sublayer and an inner large-celled sublayer (Burton et al., 1982; Barbaresi et al., 1987).

\section{Results}

\section{Glu-positive neurons in SI and SII}

Brains from cats CCG1 and CCG2 were used for quantitative study of the laminar distribution and the percentage of Gluimmunoreactive neurons. In both areas numerous Glu-positive neurons were present and displayed a brown reaction product spread throughout the perikarya and proximal dendrites (Fig. 1). In neurons cut through the soma, the nuclei appeared free of immunostaining (Fig. 1). In most cases, Glu-positive cell bodies were characterized by typical triangular shapes with apical and/or basal dendrites. These cells could be identified as pyramidal neurons (Fig. 1; see also Conti et al., 1987a). Although quantitative estimates of pyramidal versus nonpyramidal neurons were not made, in the overwhelming majority of cases Glupositive neurons appeared to belong to the former type, but some nonpyramidal Glu-positive neurons were also observed, especially in layers II, IV, and VI. Glu-positive neurons were equally numerous in SII and SI. They showed no areal preference in $3 a, 3 b, 1$, and 2 and were distributed in all cortical layers. However, counts from randomly selected cortical regions clearly showed that in both areas these neurons occurred with different frequencies in the different laminae. In a representative sample of 815 neurons collected from SI (429 neurons) and SII (386 neurons), 277 (34\%) were Glu-positive. These neurons amount- ed to $143(33.3 \%)$ in SI and $134(34.7 \%)$ in SII. Counts of labcled and unlabeled neurons present in each cortical layer revealed that in SI the highest percentages of Glu-positive neurons were in layers V (37.0\%) and III (36.0\%), followed by layers II (35.4\%), VI $(31.3 \%)$, and IV (17.9\%). In SII the highest percentages of Glu-positive neurons were in layers V and VI (35.6\% and 36.1\%, respectively), followed by layers III $(32.9 \%)$ and II $(30.9 \%)$; the lowest percentage was in layer IV (14.3\%). In layer I of both areas, Glu-positive neurons were rarely observed. Examples of the laminar distribution of Glu-positive and Glu-negative neurons in 2 vertical strips reconstructed from 2 immunocytochemically processed and counterstained sections from SI and SII are shown in Figure 2.

\section{Double-labeling experiments}

In cats CCG3-8 used for double-labeling experiments, 2 preliminary controls were carried out. The first aimed at ascertaining whether the fixation procedure, slightly different from those tested in previous experiments (Conti et al., 1987a), and/ or the HRP histochemical processing to which sections were submitted prior to immunocytochemistry, could have affected the density and/or the laminar distribution of Glu-positive neurons in SI and SII. Counts from these sections yielded results in all similar to those obtained from cats CCG1 and CCG2. The second control was devised to ascertain whether immunocytochemical processing could lead to loss of HRP from retrogradely labeled cells. This was achieved by routinely checking, in all animals used for the double-labeling experiments, for the number of HRP-labeled cells contained in sections processed for HRP to be almost equivalent to that of HRP-labeled cells found in adjacent sections processed for HRP and Glu immunolabeling.

In each cat injected with HRP, the cells of origin of 2 different corticocortical systems, one callosal and one associational, were retrogradely labeled. Injections in SI (cats CCG4-7) retrogradely labeled neurons in ipsilateral SII (SII-SI association neurons) and contralateral SI (SI-SI callosal neurons). Injections in SII (cats CCG3 and 8) retrogradely labeled neurons in ipsilateral SI (SI-SII association neurons) and contralateral SII (SII-SII callosal neurons). In all sections processed for visualization of both HRP and Glu, and containing the cells of origin of one of the 4 corticocortical systems, 3 types of labeled neurons (Fig. 3) were observed: (1) single-labeled neurons showing the brown diffuse reaction typical of Glu-positive neurons; (2) single-labeled neurons containing black HRP granules through the somata, often extended to the dendritic processes (Glu-negative association or callosal neurons); and (3) double-labeled neurons displaying both black HRP granules and brown immunostaining (Glu-positive association or callosal neurons).

In the vast majority of cases (94\%), the 2 forms of labeling were easily identified in the double-labeled neurons. However, in a few cases, HRP granules were so densely packed as to obscure the Glu reaction product, while in others the brown reaction was insufficiently intense. These cases accounted for only $6 \%$ (29 neurons) out of a total sample of 475 HRP-labeled corticocortical neurons selected from SI and SII. Of the remaining 432 neurons, 214 (49.5\%) were Glu-negative and 218 $(50.5 \%)$ Glu-positive. The proportion of single- and doublelabeled neurons in each corticocortical system investigated will be reported in the next paragraphs in which data are presented system by system and not case by case. The general topography of HRP-labeled corticocortical neurons in the respective areas 

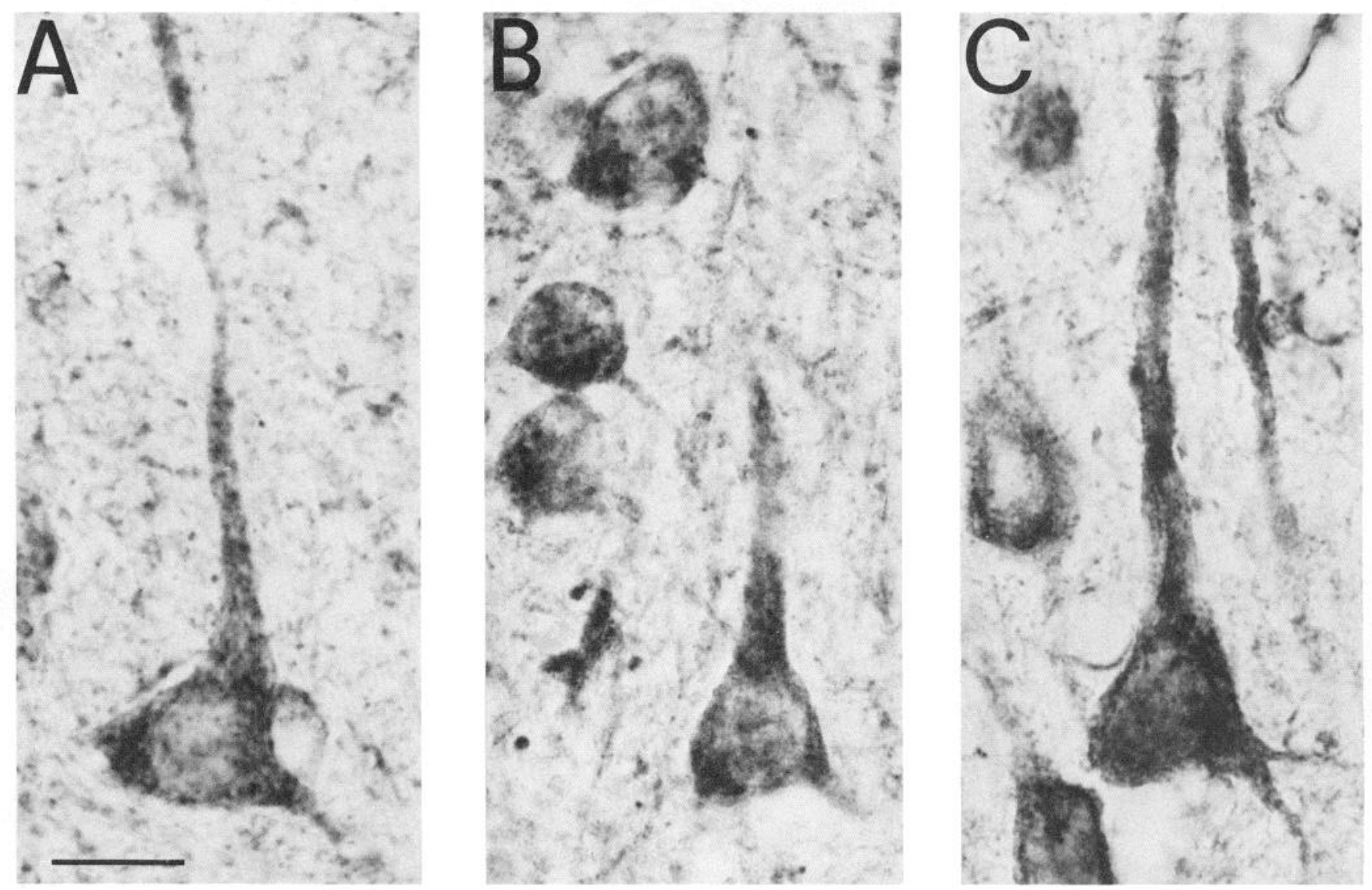

Figure 1. Photomicrographs of 3 Glu-positive pyramidal neurons: $A$, layer III, SI; $B$, layer III, SII; $C$, layer VI, SII. Scale bar, $15 \mu \mathrm{m}$.

will not be described since it was similar to that obtained in cats in previous tracing experiments on SI-SII (Manzoni et al., 1979; Burton and Kopf, 1984; Barbaresi et al., 1987) and SIISI (Alloway and Burton, 1985; Barbaresi et al., 1987) association projections and on SI-SI (Caminiti et al., 1979; Manzoni et al., 1980; Barbaresi et al., 1987) and SII-SII (Caminiti et al., 1979) callosal projections.

\section{Association neurons}

In SI, 143 HRP-labeled association neurons were considered for the counts. Fifty-nine (41.33\%) were Glu-negative, while 84 $(58.7 \%)$ were Glu-positive (Table 2$)$. Association neurons were all pyramidal in shape and, except for some in layer II (not included in the counts), all were distributed in layer III, both in its inner and outer parts. Single- and double-labeled association neurons were intermingled throughout these 2 layers and showed no apparent sublaminar segregation (Fig. 4). Perikaryal cross-sectional areas were measured from a selected sample of SI-SII association neurons of layer III, and similar values were obtained from Glu-negative (218.1 $\mu \mathrm{m}^{2}$, SD 70.5) and Glupositive (215.8 $\mu \mathrm{m}^{2}$, SD 57.2) neurons (Fig. 6A).

Of the 137 HRP-labeled association neurons sampled from SII, 70 (51.1\%) were Glu-negative and 67 (48.9\%) Glu-positive (Table 2). These neurons were all distributed in layers II-III and V-VI. As in SI, single- and double-labeled neurons were pyramidal and intermingled in these layers (Fig. 4). However, the proportions of single- and double-labeled cells were slightly different in the supragranular and infragranular layers (Table 2).

Table 2. Percentages of single- and double-labeled corticocortical neurons sampled from SI and SII of cats CCG3-CCG8

\begin{tabular}{lcccccc} 
& \multicolumn{2}{l}{ Association neurons } & & \multicolumn{2}{c}{ Callosal neurons } \\
\cline { 2 - 3 } Label & $\begin{array}{l}\text { SI-SII } \\
\text { layers II-III }\end{array}$ & $\begin{array}{l}\text { SII-SI } \\
\text { layers II-III }\end{array}$ & $\begin{array}{l}\text { SII-SI } \\
\text { layers V-VI }\end{array}$ & & $\begin{array}{l}\text { SI-SI } \\
\text { layer III }\end{array}$ & $\begin{array}{l}\text { SII-SII } \\
\text { layer III }\end{array}$ \\
\hline HRP & 59 & 44 & 26 & & 54 & 31 \\
& $(41.3 \%)$ & $(55 \%)$ & $(45.4 \%)$ & & $(60 \%)$ & $(50 \%)$ \\
HRP/Glu & 84 & 36 & 31 & & 36 & 31 \\
Total & $(58.7 \%)$ & $(45 \%)$ & $(54.6 \%)$ & & $(40 \%)$ & $(50 \%)$ \\
& 143 & 80 & 57 & & 90 & 62 \\
& $(100 \%)$ & $(100 \%)$ & $(100 \%)$ & & $(100 \%)$ & $(100 \%)$ \\
\hline
\end{tabular}


SI

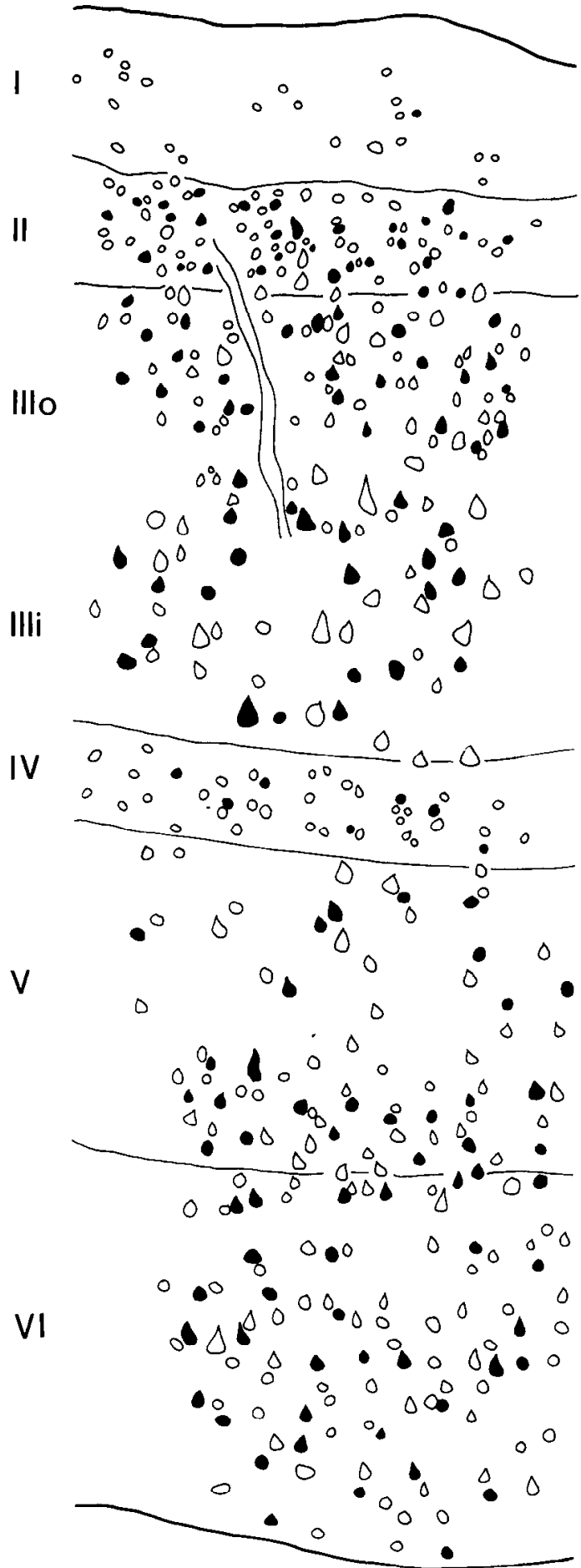

SII

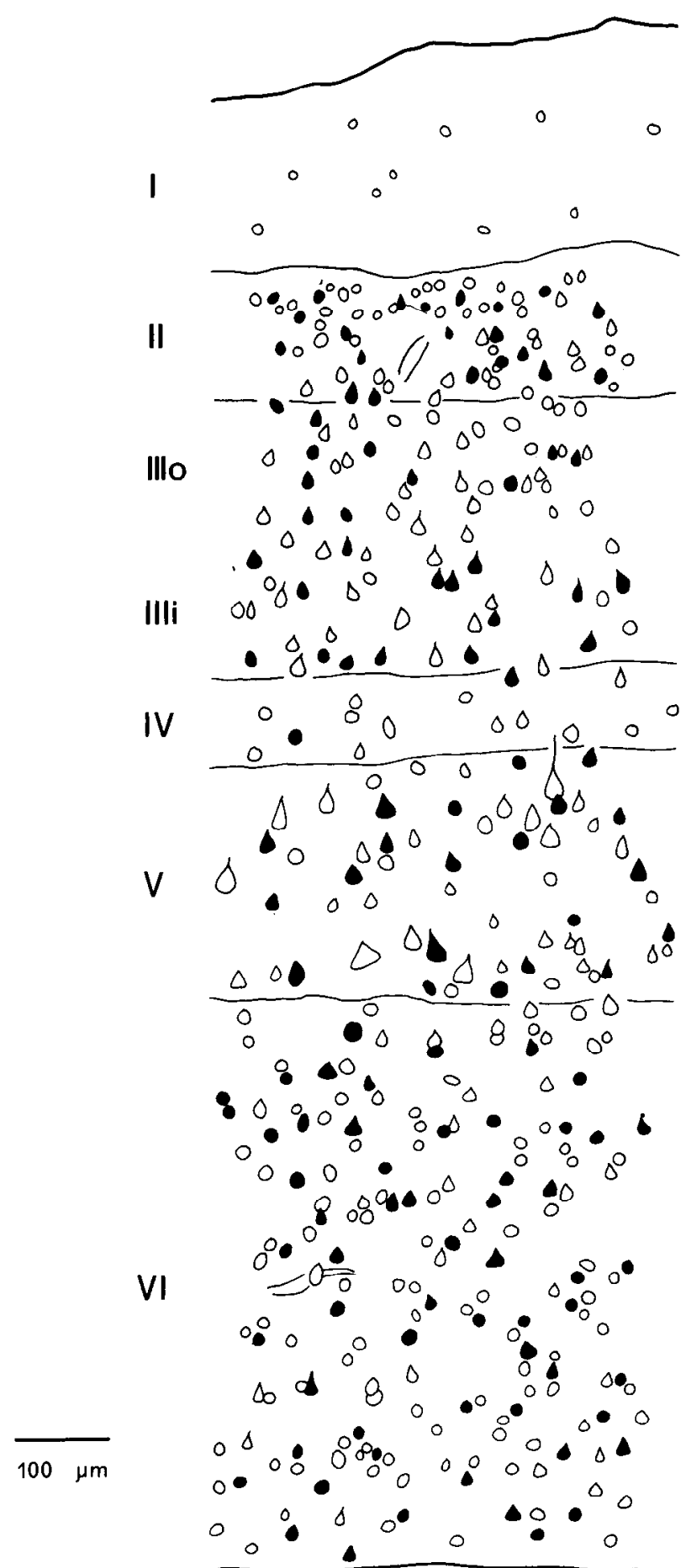

Figure 2. Distribution of Glu-positive (flled) and Glu-negative (open) neurons in 2 strips of cortex from SI and SII, reconstructed from 2 immunocytochemically processed, counterstained sections (camera lucida drawings).

Values of cross-sectional areas measured from Glu-negative and Glu-positive association neurons of supragranular layers virtually coincided $\left(206.8 \mu \mathrm{m}^{2}\right.$, SD 53.4, vs. $208.6 \mu \mathrm{m}^{2}$, SD 56.1; Fig. $6 B$ ). The slight difference between values from single- and double-labelled neurons in infragranular layers $\left(239.4 \mu \mathrm{m}^{2}, \mathrm{SD}\right.$ 70.0 vs. $221.1 \mu \mathrm{m}^{2}$, SD 61.4 ; Fig. $6 C$ ) was not significant $(p>$ $0.05)$.

\section{Callosal neurons}

Two samples of 90 and 62 HRP-labeled callosal neurons were selected from SI and SII, respectively. Of the first sample, 36 (40\%) neurons were Glu-negative and 54 (60\%) Glu-positive, while in the second sample exactly $50 \%$ of neurons were Glunegative and 50\% Glu-positive (Table 2). Single- and double- 

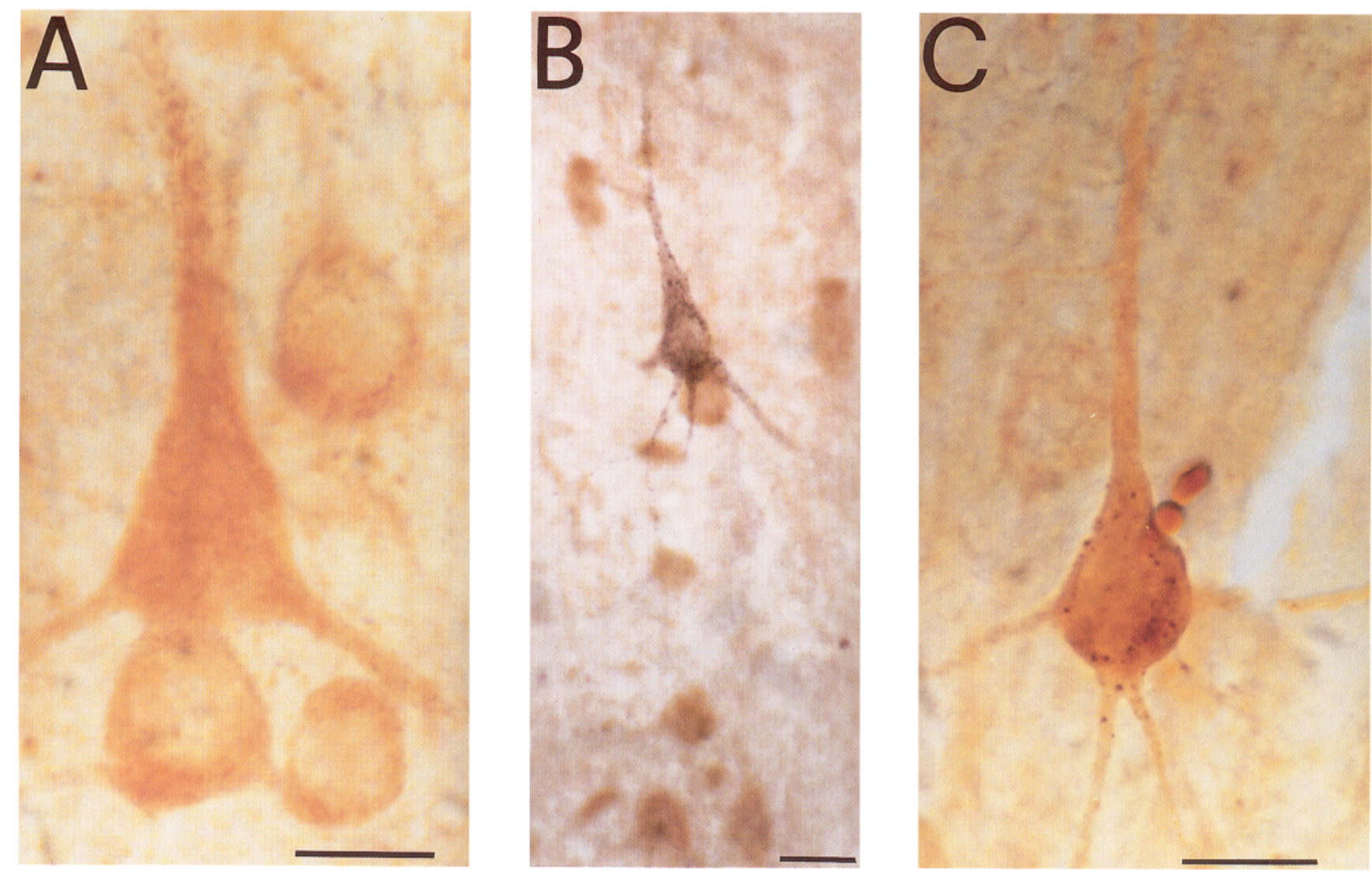

Figure 3. Photomicrographs showing the 3 types of neuronal labeling obtained with the combined HRP retrograde transport-immunocytochemistry technique. $A$, Single-labeled neurons showing the pale brown, diffuse staining typical of Glu-positive cells. $B$, Single-labeled neuron displaying black HRP granular reaction product. $C$, Double-labeled neuron with both black HRP granules and the diffuse brown reaction product. Scale bar, 20 $\mu \mathrm{m}$ for $A$ and $C ; 35 \mu \mathrm{m}$ for $B$.

labeled neurons in the 2 samples were all pyramidal and were intermingled in the outer and inner parts of layer III (Fig. 5). Some Glu-negative and Glu-positive neurons (not included in the counts) were also observed in the infragranular layers of SI and SII. Perikaryal cross-sectional areas of Glu-negative and Glu-positive, and SI-SI callosal neurons were similar (261.1 $\mu \mathrm{m}^{2}$, SD 60.0 , vs. $262.8 \mu \mathrm{m}^{2}$, SD 71.6; Fig. $6 D$ ). Mean values from single- and double-labeled SII-SII callosal neurons (210.0 $\mu \mathrm{m}^{2}$, SD 64.0 , vs. $243.7 \mu \mathrm{m}^{2}$, SD 71.2 ; Fig. $6 E$ ) were slightly, but not significantly, different $(p>0.05)$.

\section{Data from thin sections}

Data on double-labeling experiments reported above were all obtained from $25-\mu$ m-thick sections. Despite the rather strict criteria adopted to select neurons for counts (see Materials and Methods), double-labeled corticocortical neurons were liable to be underestimated because of the limited penetration of the antibody. Counts were therefore carried out in 5- $\mu$ m-thick sections from SI of cat CCG8, in which HRP was injected in the ipsilateral SII. A total of $58 \mathrm{HRP}$-labeled SI-SII association neurons were sampled from 8 sections. Of these neurons, 15 (25.9\%) were Glu-negative and 43 (74.1\%) Glu-positive (Fig 7).

\section{Discussion}

The present experiments show that in the SI and SII of cats a large share of corticocortical projecting neurons, identified by means of retrograde labeling with HRP, were immunoreactive to the anti-Glu serum. These neurons, therefore, probably use Glu, or a closely related compound, as their synaptic transmitter. Before dealing with this issue, some technical aspects upon which the validity of the present results depends need to be discussed.

\section{Technical considerations}

Three main technical factors must be considered: (1) the specificity of the anti-Glu serum; (2) its selectivity in labeling the transmitter pool of Glu; and (3) the technique used for doublelabeling of corticocortical neurons.

The specificity of the anti-Glu serum used in the present experiments is discussed in a recent paper (Hepler et al., 1988). In brief, both immunocytochemistry and immunoblot analysis showed that this antiserum does not cross-react with other chemically related and biologically active compounds, including Asp (Conti et al., 1987b; Hepler et al., 1988). A strictly related, although different, question is whether the immunostaining of neurons observed in these experimental conditions is related to the transmitter pool, to the metabolic pool of Glu, or both. This question was discussed in detail in another report by Conti et al. (1987a), who concluded that the immunoreactivity obtained in cortical neurons of rats and monkeys with the same anti-Glu serum used in the present experiments is likely to reflect the cellular levels of this acidic amino acid related to neurotransmission.

Several techniques devised over the last 10 years have attempted to combine retrograde tracing with neurotransmitter 
SI ASS

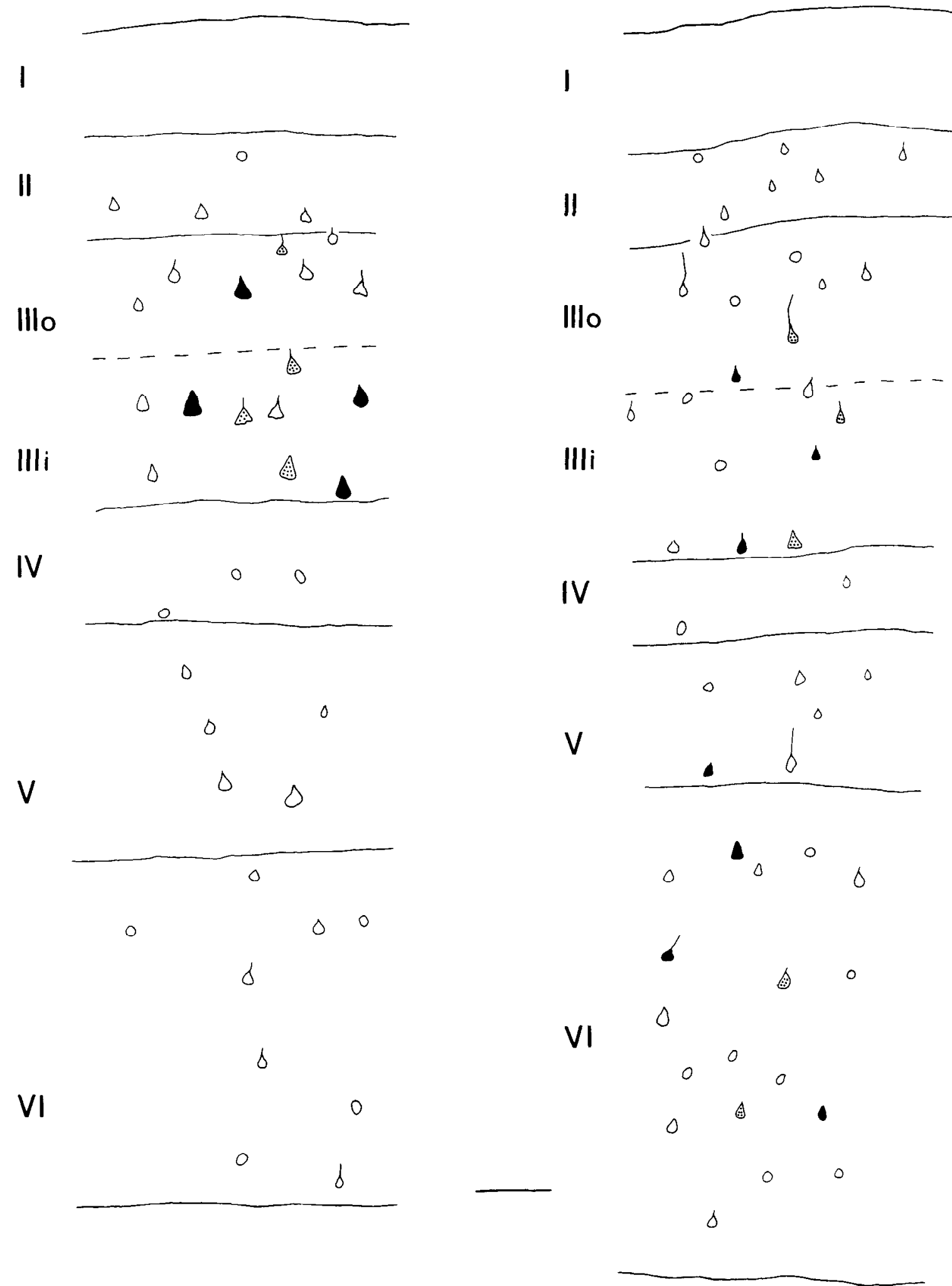

\section{SII ASS}

III

$$
\overline{6}-0-\frac{1}{6}-\cdots
$$




\section{SI CALL}

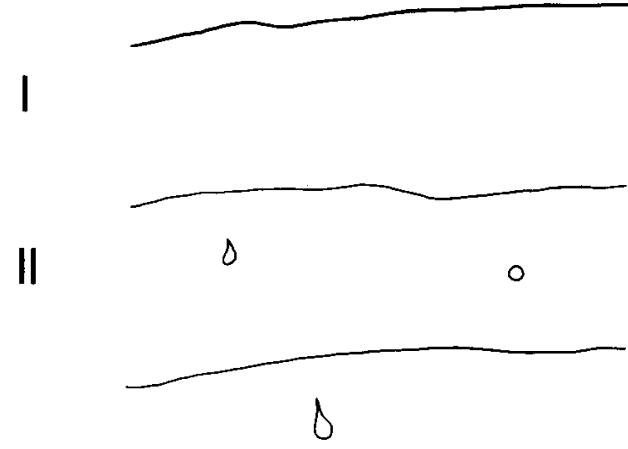

Illo

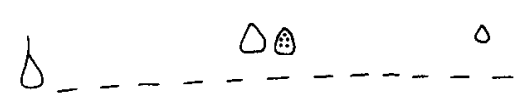

IIIi

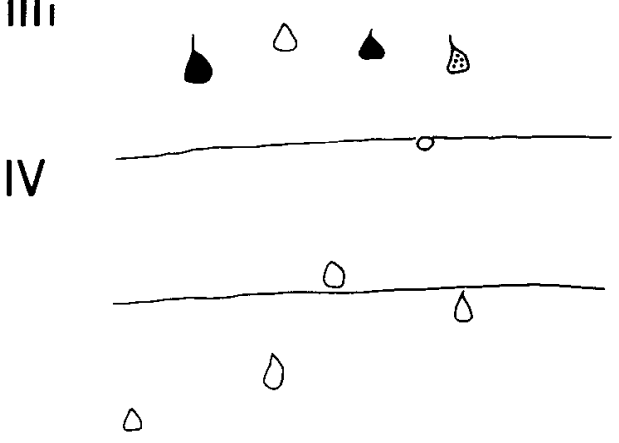

V

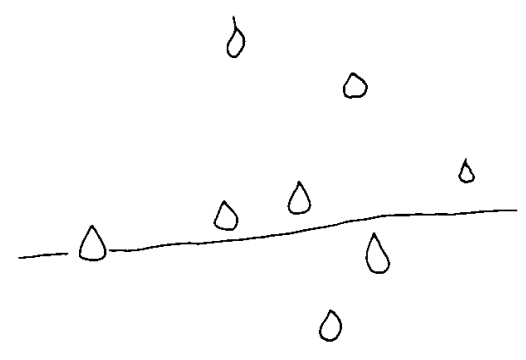

$\Delta$

0

VI
$S \| C A L L$

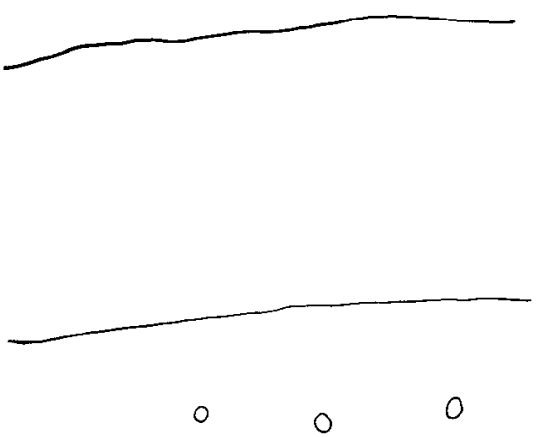

II

0

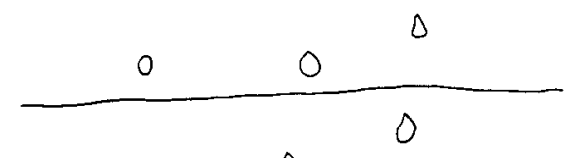

IIIo

IIIi

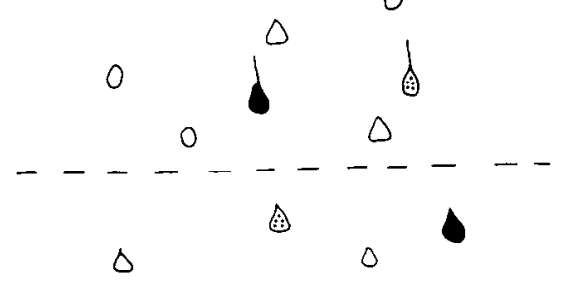

IV

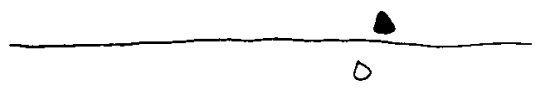

V

0

$\Delta$

0

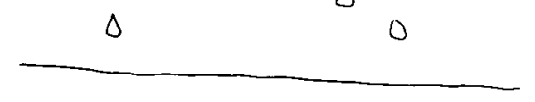

$\Delta$

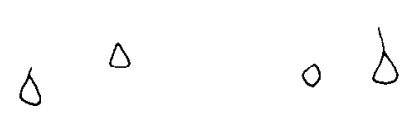

o

$\Delta$

0

VI

0

O

6

0

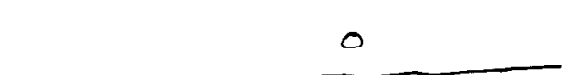

Figure 5. Laminar distribution in SI (cat CCG7) and SII (cat CCG3) of Glu-positive neurons (open), HRP-labeled, Glu-negative callosal neurons (stippled), and HRP-labeled, Glu-positive callosal neurons (filled). Camera lucida drawing from 2 immuncytochemically processed, noncounterstained sections. 

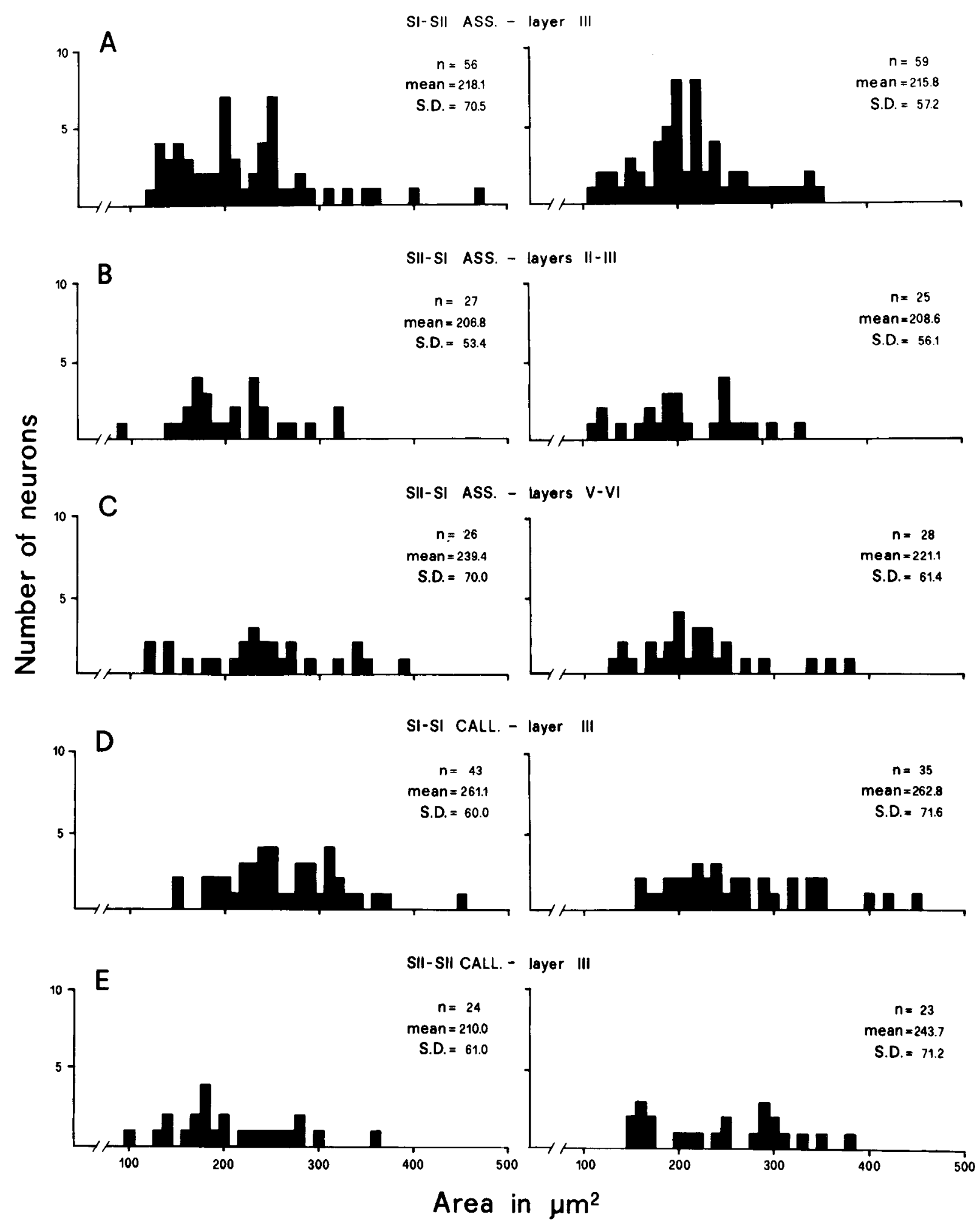

Figure 6. Histograms of perikaryal cross-sectional areas from different samples of corticocortical neurons of SI and SII. The left and right vertical columns refer to single-labeled (HRP) and double-labeled (HRP/Glu) neurons, respectively. Each horizontal row $(A-E)$ refers to neurons of the same corticocortical projection.

immunocytochemistry (Ljungdahl et al., 1975; see Hökfelt et al., 1983, for a review). Every method employed so far entails a series of advantages and disadvantages and "no one is perfect" (Skirboll et al., 1984). The main advantages of the method adopted in this study, i.e., Glu immunocytochemistry in conjunction with HRP retrograde tracing, are (1) absence of fading of the retrograde tracer; (2) simultaneous visualization of the 2 forms of labeling and ease to ascertain their presence in the 

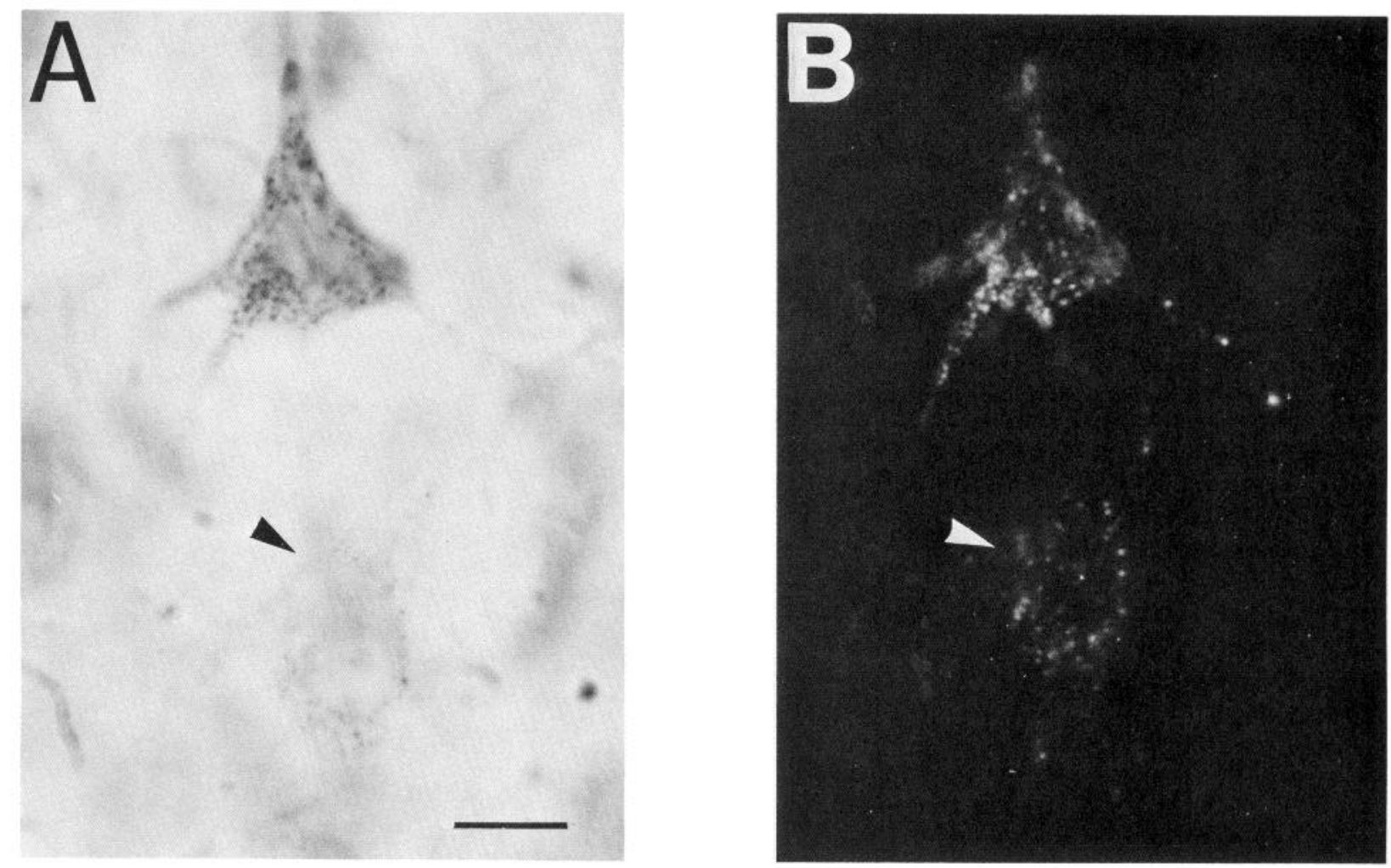

Figure 7. Bright-field $(A)$ and dark-field $(B)$ photomicrographs showing a HRP-labeled (arrow) and a double-labeled SI-SII association neuron in layer III of SI. Immunocytochemically processed, noncounterstained section (5 $\mu$ m thick) from cat CCG8. Scale bar, $15 \mu \mathrm{m}$.

same cell, which makes identification of double-labeled neurons very reliable; (3) possibility of counterstaining sections with Nissl methods, leaving both types of labeling unaffected; and (4) absence of crossed influences between HRP and immunocytochemical procedure, i.e., the first processing does not alter the number of neurons labeled with immunocytochemistry and vice versa. The main disadvantage is the low sensitivity of the cobalt-enhanced DAB method for visualization of HRP compared with other more sensitive HRP methods (Mesulam and Rosene, 1979). A strictly related problem is that of fixation procedure since in order to obtain the best conditions for Gluimmunoreactivity visualization (Conti et al., 1987a), glutaraldehyde, which is the fixative of choice for HRP histochemistry (Rosene and Mesulam, 1978), was not used. The fixation procedure adopted in our double-labeling experiments was, however, the most suited to these kinds of experiments for 2 reasons. First, the percentages and the layer distributions of Glu-positive neurons in SI and SII of cats used for double-labeling experiments were comparable to those obtained in animals CCG1 and 2 , whose brains were fixed according to a procedure successfully tested in previous experiments on the somatic sensory cortex of rats and monkeys (Conti et al., 1987a), in which the anti-Glu serum was assumed to give a complete picture of cortical Glupositive neurons. Second, density of HRP-labeled neurons was still satisfactory in all corticocortical systems investigated and the topography and laminar patterns of these corticocortical neurons were in agreement with data reported in several anatomical experiments on callosal and association projections of SI and SII of cats (Caminiti et al., 1979; Manzoni et al., 1979, 1980; McKenna et al., 1981; Burton and Kopf, 1984; Alloway and Burton, 1985; Barbaresi et al., 1987). The number of HRP- labeled neurons in all neuronal systems depends on several technical factors (Jones, 1975), and mainly on histochemical methods and fixation procedures. Therefore, while a number of corticocortical neurons is certain to have escaped histochemical visualization in our experiments, it is likely that they escaped visualization regardless of their chemical identity and were randomly distributed between Glu-negative and Glu-positive neurons.

The last problem related to double-labeling is the potential occurrence of sampling bias due to the limited penetration of the antiserum in $25-\mu$ m-thick sections compared with the free penetration of HRP histochemistry reagents, which can determine underestimation of the total number of double-labeled neurons (Bowker et al., 1982). Results from 5- $\mu$ m-thick sections show that this sampling bias really occurs: in thin sections the percentage of double-labeled SI-SII association neurons was higher $(75 \%)$ than that observed in thicker sections $(60 \%)$. The ratio of the percentages of double-labeled neurons in thin and thick sections yields a correction factor of 1.25 . Underestimation of number of double-labeled cells is unrelated to neuronal systems since this bias depends upon mere physical factors. Therefore, we feel that the correction factor should be used in all 4 corticocortical systems to obtain a final percentage representing to a better approximation the real estimate of Glu-positive corticocortical neurons.

\section{Glu-positive corticocortical neurons and Glu-ergic subpopulations}

In the 4 corticocortical systems studied in the present experiments, numerous projecting neurons were immunoreactive for Glu and amounted to $40.0-58.7 \%$ of HRP-labeled neurons. 
However, by applying the above mentioned correction factor, the percentage of Glu-positive neurons ranged from 50.0 to $73.4 \%$ of the sample of corticocortical neurons identified in SI and SII. The involvement of excitatory amino acids in corticocortical synaptic transmission has been previously suggested (Streit, 1980; Fisher et al., 1982; Hicks and Guedes, 1983; Hicks et al., 1985), and recent $\mathrm{D}^{3} \mathrm{H}$-Asp experiments showed that the neurons of origin of the same corticocortical projections investigated in the present research could be retrogradely labeled with the tritiated marker (Barbaresi et al., 1987). The results obtained with the anti-Glu serum extend these data and answer some of the questions raised in the introduction. Since $D^{-3}$ II-Asp retrogradely labels both Glu-ergic and Asp-ergic neurons (Streit, 1980; Cuénod et al., 1982), the question of whether the neurotransmitter used by corticocortical neurons is Glu or Asp was unsettled. The anti-Glu serum, on the contrary, does not crossreact with Asp and therefore selectively labels only neurons with high intracellular levels of Glu (Conti et al., 1987a; Hepler et al., 1988).

Another important result from the present experiments is that numerous association and callosal neurons in lower layer III, a source of corticocortical fibers in all mammals (Jones, 1984), were immunoreactive for Glu, whereas they were rarely labeled with $\mathrm{D}^{3} \mathrm{H}$-Asp (Barbaresi et al., 1987). It was proposed that these neurons could be a class of Glu/Asp-ergic neurons not incorporating this amino acid or, alternatively, a population of neurons using other neurotransmitters (Barbaresi et al., 1987). Since $\mathrm{D}-{ }^{3} \mathrm{H}-\mathrm{Asp}$ is known to label Glu-ergic neurons also, it can be safely assumed that the numerous Glu-positive corticocortical neurons found in the present experiments in the lower layer III were rarely labeled with $D^{-3} \mathrm{H}$-Asp because they may be a layer-specific subpopulation of Glu-ergic neurons unable to incorporate $\mathrm{D}^{-3} \mathrm{H}-\mathrm{Asp}$. The existence of subpopulations of Gluergic neurons was also proposed by Conti et al. (1987a) on the basis of evidence from immunocytochemical experiments showing that neurons immunoreactive for Glu (Conti et al., 1987a) and glutaminase (Donoghue et al., 1985), an enzyme involved in Glu metabolism, are characterized by a different laminar distribution in the cerebral cortex of rats and monkeys. Both sets of data on the existence of Glu-ergic neuronal subpopulations suggest that the anti-Glu serum could label all putative Glu-ergic neurons in the cerebral cortex, whereas other probes so far used to identify such neurons probably label only a fraction.

\section{Other possible neurotransmitters of corticocortical neurons}

The present results give clear evidence that in all layers containing Glu-positive corticocortical neurons, HRP-labeled cell bodies were present and were unlabeled with the anti-Glu serum. These neurons amounted to about a third of all corticocortical neurons sampled from SI and SII. Since, as reported above, the anti-Glu serum used in the present research appears to be able to provide a nearly complete picture of putative Glu-ergic neurons present in the ccrcbral cortex (Conti et al., 1987a), it follows that HRP-positive, Glu-negative neurons are not Glu-ergic.

At present no experimental data are available on other possible neurotransmitters in corticocortical fibers, and many unknown substances could have synaptic effects. Among the endogenous chemicals supposed to exert excitatory action in the cerebral cortex (see Luini et al., 1984), 2 neurotransmitter candidates in corticocortical fibers are Asp and homocysteic acid
(HCA). Evidence for Asp as a neurotransmitter is not as thorough as it is for Glu, yet this amino acid is generally considered an excitatory synaptic transmitter (see Streit, 1984), and some lines of evidence, although indirect, support this hypothesis. Recent neuropharmacological experiments on visual areas of cats suggest that Asp may be an excitatory transmitter in corticocortical pathways (Hicks et al., 1985). The population of association and callosal neurons labeled with $\mathrm{D}^{-3} \mathrm{H}-\mathrm{Asp}$ in previous experiments might indeed include some Asp-ergic neurons (Barbaresi et al., 1987). Immunocytochemical experiments showed that there exists in the cerebral cortex of rats a population of neurons immunoreactive for Asp (Campistron et al., 1986; Conti et al., 1987b). Asp- and Glu-positive neurons form 2 distinct populations, so neurons immunoreactive for Asp were not immunoreactive for Glu, and vice versa, except for a few neurons (about 10\%) that reacted with both antisera. However, these populations were both composed of pyramidal cells and showed similar laminar distributions and perikaryal cross-sectional areas (Conti et al., 1987b). Corticocortical neurons that were not immunoreactive for Glu in our sample were all pyramidal, and soma size and laminar distributions were similar to those of Glu-positive neurons. Other immunocytochemical experiments showed cortical neurons immunoreactive for Aspaminotransferase (ATT), an enzyme participating in Asp metabolism (Donoghue et al., 1985). Interpretation of experiments involving Asp and AI"I immunocytochemistry must be very conservative since both substances could be related either to the metabolic pool of Asp or to the GABA metabolism (Donoghue et al., 1985; Conti et al., 1987b; Hepler et al., 1988). Further investigations are therefore in order to discover whether Asp is indeed the neurotransmitter of those corticocortical neurons that were Glu-negative in our experiments.

As far as HCA is concerned, it was shown that this substance has strong excitatory effects on mammalian neurons (Curtis and Watkins, 1963). Do et al. (1986a, b) recently showed a potassium-induced, calcium-dependent release of HCA from various regions of the nervous system and found that the ratio of stimulated and resting efflux was higher in the neocortex than in all other structures examined. These authors proposed a role for $\mathrm{HCA}$ as a cortical neurotransmitter.

\section{Postsynaptic mechanisms}

The excitatory effects exerted by Glu-releasing corticocortical fibers on target neurons depends on several factors and, among others, on the type of postsynaptic receptor (Mayer and Westbrook, 1987). Three or more types of excitatory amino acid receptors, named after their specific agonists and supposed to have differential effects on postsynaptic membranes, were proposed in the CNS of vertebrates (Watkins and Evans, 1981; McLennan, 1983; see Mayer and Westbrook, 1987). The involvement of one of them, the $N$-methyl-D-Asp (NMDA) receptor, in the responses of cortical neurons to corpus callosum stimulation has recently been suggested by Thomson (1986; see also Hicks and Guedes, 1983). In isolated slices of rat sensorimotor cortex, Thomson stimulated callosal fibers and recorded from pyramidal neurons a type of excitatory postsynaptic potential with striking similarities to the responses of the same neurons to iontophoretically applied NMDA in terms of voltage relations, $\mathrm{Mg}^{2+}$ concentration dependence, and sensitivity to NMDA antagonists. These data, together with the present demonstration that callosal fibers are probably Glu-ergic, seem to indicate one mode of operation of at least some callosal synapses 
(and possibly of association synapses, too). Under physiological conditions, NMDA receptors do not mediate fast excitatory responses but, rather, long-lasting effects that are subthreshold for cell firing (Mayer and Westbrook, 1987). These effects are supposed to be involved in some forms of synaptic plasticity, such as long-term potentiation in the hippocampus (Collingridge et al., 1983) and synaptic plasticity in the kitten visual cortex (Tsumoto et al., 1987), and mainly "to boost incoming depolarization from other inputs" (Mayer and Westbrook, 1987). These findings may have a connection with intracellular studies in vivo showing that, in many visual (Toyama et al., 1974; Singer et al,. 1975; Innocenti, 1980) and somatosensory (Innocenti et al., 1972) cortical neurons, high-frequency repetitive stimulation of callosal fibers causes slowly rising, low-amplitude postsynaptic depolarization that rarely initiated action potentials. All these data would suggest that Glu-ergic callosal fibers, through their NMDA receptors, may well provide the chemical basis for the involvement of the callosum in "plastic functions."

Note added in proof: Recently, Conti et al. (1988) showed that about half of corticocortical neurons in cat SI and SII were immunoreactive to an anti-Asp serum (Hepler et al., 1988). This finding brings some evidence to the hypothesis that Glu-negative corticocortical neurons might use Asp as a neurotransmitter (see Discussion).

\section{References}

Alloway, K. D., and H. Burton. (1985) Homotypical ipsilateral cortical projections between somatosensory areas I and II in the cat. Neuroscience $14: 15-35$.

Balcar, V. J., and G. A. R. Johnston (1972) The structural specificity of the high affinity uptake of L-glutamate and aspartate by rat brain slices. J. Neurochem. 19: 2657-2666.

Barbaresi, P., M. Fabri, F. Conti, and T. Manzoni (1987) D- $\left[{ }^{3} \mathrm{H}\right]$ Aspartate retrograde labelling of callosal and association neurones of somatosensory areas I and II of cats. J. Comp. Neurol. 263: 159178.

Baughman, R. W., and C. D. Gilbert (1981) Aspartate and glutamate as possible neurotransmitters in the visual cortex. J. Neurosci. 1:427439.

Bowker, R. M., K. N. Westlund, M. C. Sullivan, and J. D. Coulter (1982) A combined retrograde transport and immunocytochemical staining method for demonstrating the origins of serotoninergic projections. J. Histochem. Cytochem. 30: 805-810.

Burton, H., and E. M. Kopf (1984) Ipsilateral cortical connections from the second and the fourth somatic sensory areas in the cat. $J$. Comp. Neurol. 225: 527-553.

Burton, H., G. Mitchell, and D. Brent (1982) Second somatic sensory area in the cerebral cortex of cats: Somatotopic organization and cytoarchitecture. J. Comp. Neurol. 210: 109-135.

Caminiti, R., G. M. Innocenti, and T. Manzoni (1979) The anatomical substrate of the callosal messages from SI and SII in the cat. Exp. Brain Res. 35: 295-314.

Campistron, G., R. M. Buijs, and M. Geffard (1986) Specific antibodies against aspartate and their immunocytochemical application in the rat brain. Brain Res. 365: 179-184.

Collingridge, G. L., S. J. Kehl, and H. McLennan (1983) Excitatory amino acids in synaptic transmission in the Schaffer collateral commissural pathway of the rat hippocampus. J. Physiol. (Lond.) 334: $33-46$.

Conti, F., A. Rustioni, P. Petrusz, and A. Towle (1987a) Glutamatepositive neurons in the somatic sensory cortex of rats and monkeys. J. Neurosci. 7: 1887-1901.

Conti, F., A. Rustioni, and P. Petrusz (1987b) Co-localization of glutamate and aspartate immunoreactivity in neurons of the rat somatic sensory cortex. In Excitatory Amino Acid Transmission, T. P. Hicks, D. Lodge, and H. McLennan, eds., pp. 169-172, Liss, New York.

Conti, F., M. Fabri, and T. Manzoni (1987c) A combined retrograde transport and immunocytochemical study of glutamatergic somato- sensory cortico-cortical projections in the cat. I. Callosal projections. Neuroscience (Suppl.) 22: 5708.

Conti, F., M. Fabri, and T. Manzoni (1988) Aspartate-positive corticocortical neurons in the somatic sensory areas I and II of cats. In Recent Advances in Excitatory Amino Acid Research, E. A. Cavalheiro, J. Lehmann, and L. Turski, eds., Liss, New York (in press).

Cuénod, M., P. Bagnoli, A. Beaudet, A. Rustioni, L. Wiklund, and P. Streit (1982) Transmitter-specific retrograde labeling of neurons. In Cytochemical Methods in Neuroanatomy, V. Chan-Palay and S. L. Palay, eds., pp. 17-44, Liss, New York.

Curtis, D. R., and J. C. Watkins (1963) Acidic amino acids with strong excitatory actions on mammalian neurones. J. Physiol. (Lond.) 166 : $1-14$.

Do, K. Q., M. Mattenberger, P. Streit, and M. Cuénod (1986a) In vitro release of endogenous excitatory sulfur-containing amino acids from various rat brain regions. J. Neurochem. 46: 779-786.

Do, K. Q., P. L. Herrling, P. Streit, W. A. Turski, and M. Cuénod (1986b) In vitro release and electrophysiological effects in situ of homocysteic acid, an endogenous N-methyl-(D)-aspartate acid antagonist, in the mammalian striatum. J. Neurosci. 6: 2226-2234.

Donoghue, J. P., R. J. Wenthold, and R. A. Altschuler (1985) Localization of glutaminase-like and aspartate aminotransferase-like immunoreactivity in neurons of cerebral neocortex. J. Neurosci. 5:25972608.

Fagg, G. E., and A. C. Foster (1983) Amino acid neurotransmitters and their pathways in the mammalian nervous system. Neuroscience 9: 701-719.

Felleman, D. J., J. T. Wall, C. G. Cusick, and J. H. Kaas (1983) The representation of the body surface in SI of cats. J. Neurosci. 3: 16481669.

Fisher, B. O., O. P. Ottersen, and J. Storm-Mathisen (1982) Axonal transport of $\mathrm{D}-\left[{ }^{3} \mathrm{H}\right]$ aspartate in the claustrocortical projection. Neuroscience (Suppl. 2): S69.

Fonnum, F. (1984) Glutamate: A neurotransmitter in the mammalian brain. J. Neurochem. 42: 1-11.

Fonnum, F., and D. Malthe-Sorenssen (1981) Localization of glutamate neurons. In Glutamate: Transmitter in the Central Nervous System, P. J. Roberts, J. Storm-Mathisen, and G. A. R. Johnson, eds., pp. 205-222, Wiley, New York.

Hassler, R., and K. Muhs-Clement (1964) Architektonischer aufban des sensorimotorischen und parietalen cortex der katze. J. Hirnforsch. 6: $377-420$.

Hepler, J. R., C. Toomin, K. D. McCarthy, F. Conti, G. Battaglia, A. Rustioni, and P. Petrusz (1988) Characterization of antisera to glutamate and aspartate. J. Histochem. Cytochem. 36: 13-22.

Hicks, T. P., and R. C. A. Guedes (1983) Neuropharmacological properties of electrophysiologically identified, visually responsive neurones of the posterior lateral suprasylvian area. A microiontophoretic study. Exp. Brain Res. 49: 157-173.

Hicks, T. P., W. D. Ruwe, W. L. Veale, and J. Veenhuizen (1985) Aspartate and glutamate as synaptic transmitters of parallel visual cortical pathways. Exp. Brain Res. 58: 421-425.

Hökfelt, T., G. Skagerberg, L. Skirboll, and A. Björklund (1983) Combination of retrograde tracing and neurotransmitter histochemistry. In Handbook of Cherrical Neuroanatomy, Vol. 1, Methods in Chemical Neuroanatomy, A. Björklund and T. Hökfelt, eds., pp. 228-285, Elsevier, New York.

Hsu, S. M., L. Raine, and H. Fanger (1981) Use of avidin-biotinperoxidase complex (ABC) in immunoperoxidase techniques: A comparison between $\mathrm{ABC}$ and unlabeled antibody (PAP) procedures. J. Histochem. Cytochem. 29: 557-580.

Innocenti, G. M. (1980) The primary visual pathway and functional aspects in the cat. Arch. Ital. Biol. 118: 124-188.

Innocenti, G. M., T. Manzoni, and G. Spidalieri (1972) Peripheral and transcallosal reactivity of neurones within SI and SII cortical areas. Segmental divisions. Arch. Ital. Biol. 110:415-433.

Johnson, J. L. (1972) Glutamic acid as a synaptic transmitter in the nervous system. A review. Brain Res. 37: 1-19.

Jones, E. G. (1975) Possible determinants of the degree of retrograde labeling with horseradish peroxidase. Brain Res. 85: 249-253.

Jones, E. G. (1984) Laminar distribution of cortical efferent cells. In Cerebral Cortex, Vol. 1, Cellular Components of the Cerebral Cortex, A. Peters and E. G. Jones, eds., pp. 521-553, Plenum, New York.

Jones, E. G. (1985) The Thalamus, XVII, 935, Plenum Press, New York

Krnjević, K., and J. K. Phillis (1963) Iontophoretic studies of neurons 
in the mammalian cerebral cortex. J. Physiol. (Lond.) 165: 274-304. Krnjević, K., and J. K. Phillis (1974) Chemical nature of synaptic transmission in vertebrates. Physiol. Rev. 54: 418-540.

Ljungdahl, A., T. Hökfelt, M. Goldstein, and D. Park (1975) Retrograde peroxidase tracing of neurons combined with transmitter histochemistry. Brain Res. 84: 313-319.

Luini, A., N. Tal, O. Goldberg, and V. I. Teichberg (1984) An evaluation of selected brain constituents as putative excitatory neurotransmitters. Brain Res. 324: 271-277.

Manzoni, T., R. Caminiti, G. Spidalieri, and E. Morelli (1979) Anatomical and functional aspects of the associative projection from the somatic area SI to SII. Exp. Brain Res. 34: 453-470.

Manzoni, T., P. Barbaresi, E. Bellardinelli, and R. Caminiti (1980) Callosal projections from the two body midlines. Exp. Brain Res. 39: $1-9$.

Manzoni, T., P. Barbaresi, and M. Fabri (1986) D-[3 H]-Aspartate retrograde labelling of association neurones in area SI of the cat. Neurosci. Lett. 67: 175-180.

Manzoni, T., F. Conti, and M. Fabri (1987) A combined retrograde transport and immunocytochemical study of glutamatergic somatosensory cortico-cortical projections in the cat. II. Association projections. Neuroscience 22: 5708

Matute, C., and P. Streit (1985) Selective retrograde labeling with D- $\left[{ }^{3} \mathrm{H}\right]$ Aspartate in afferents to the mammalian superior colliculus. J. Comp. Neurol. 241: 34-49.

Mayer, M. L., and G. L. Westbrook (1987) The physiology of excitatory amino acids in the vertebrate central nervous system. Prog. Neurobiol. 28: 197-276.

McKenna, T. M., B. L. Whitsel, D. A. Dreyer, and C. B. Metz (1981) Organization of cat anterior parietal cortex: Relations among cytoarchitecture, single neuron functional properties and interhemispheric connectivity. J. Neurophysiol. 45: 667-697.

McLennan, H. (1983) Receptors for excitatory amino acids in the mammalian central nervous system. Prog. Neurobiol. 20: 251-271

Mesulam, M. M., and D. L. Rosene (1979) Sensitivity in horseradish peroxidase neurohistochemistry. A comparative and quantitative study of nine methods. J. Histochem. Cytochem. 27: 763-773.

Ottersen, O. P., and J. Storm-Mathisen (1984) Glutamate and GABAcontaining neurons in the mouse and rat brain, as demonstrated with a new immunocytochemical technique. J. Comp. Neurol. 229: 374392.

Rosene, D. L., and M. M. Mesulam (1978) Fixation variables in horseradish peroxidase neurohistochemistry. I. The effects of fixation time and perfusion procedures upon enzymatic activity. J. Histochem. Cytochem. 26: 28-39.
Rustioni, A., and M. Cuénod (1982) Selective retrograde transport of D-aspartate in spinal interneurons and cortical neurons of rats. Brain Res. 236: 143-155.

Rustioni, A., D. E. Schmechel, R. Spreafico, S. Cheema, and M. Cuénod (1983) Excitatory and inhibitory amino acid putative neurotransmitters in the ventralis posterior complex: An autoradiographic and immunocytochemical study in rats and cats. In Somatosensory Integration in the Thalamus, G. Macchi, A. Rustioni, and R. Spreafico, eds., pp. 365-383, Elsevier, Amsterdam.

Singer, W., F. Tretter, and M. Cynader (1975) Organization of cat striate cortex: A correlation of receptive-field properties with afferent and efferent connections. J. Neurophysiol. 38: 1080-1098.

Skirboll, L., T. Hökfelt, G. Norell, O. Phillipson, H. G. J. M. Kuypers, M. Bentivoglio, C. E. Catsman-Berrevoets, T. J. Visser, H. Steinbush, A. Verhotstad, A. C. Cuello, M. Goldstein, and M. Brownstein (1984) A method for specific transmitter identification of retrogradely labeled neurons: Immunofluorescence combined with fluorescence tracing. Brain Res. Rev. 8: 99-127.

Sternberger, L. A. (1986) Immunocytochemistry, 3rd ed., Wiley, New York.

Storm-Mathisen, J., A. K. Leknes, A. T. Bore, J. L. Vaaland, P. Edminson, F. M. S. Haug, and O. P. Ottersen (1983) First visualization of glutamate and $\mathrm{G} \Lambda \mathrm{B} \Lambda$ in neurons by immunocytochemistry. Nature 301: 517-520.

Streit, P. (1980) Selective retrograde labeling indicating the transmitter of neuronal pathways. J. Comp. Neurol. 191:429-463.

Streit, P. (1984) Glutamate and aspartate as transmitter candidates for systems of the cerebral cortex. In Cerebral Cortex, Vol. 2, Functional Properties of Cortical Cells, E. G. Jones and A. Peters, eds., pp. 119-143, Plenum, New York.

Thomson, A. M. (1986) A magnesium-sensitive post-synaptic potential in rat cerebral cortex resembles neuronal responses to $\mathrm{N}$-methylaspartate. J. Physiol. (Lond.) 370: 531-549.

Toyama, K., K. Matsunami, T. Ohno, and S. Tokashiki (1974) An intracellular study of neuronal organization in the visual cortex. Exp. Brain Res. 21: 45-66.

Tsumoto, T., K. Hagihara, H. Sato, and Y. Hata (1987) NMDA receptors in the visual cortex of young kittens are more effective than those of adult cats. Nature 327: 513-514.

Watkins, J. C, and R. H. Evans (1981) Excitatory amino acid transmitters. Annu. Rev. Pharmacol. Toxicol. 21: 165-204.

Wiklund, L., G. Toggenburger, and M. Cuénod (1984) Selective retrograde labelling of the rat olivocerebellar climbing fiber system with D- $\left[{ }^{3} \mathrm{H}\right]$ aspartate. Neuroscience 13: $441-468$. 